\title{
LSI 上MEMSによるへテロ集積化
}

\author{
江刺 正喜*, 田中 秀治**
}

\section{Heterogeneous Integration of MEMS on LSI}

Masayoshi ESASHI* and Shuji TANAKA**

* 東北大学マイクロシステム融合研究開発センター（９ 980-0845 仙台市青葉区荒巻字青葉 519-1176）

***東北大学大学院工学研究科ロボティックス専攻（９ 980-8579 仙台市青葉区荒巻字青葉 01）

* Micro System Integration Center, Tohoku University (519-1176 Aramaki-Aza-Aoba, Aoba-ku. Sendai 980-0845)

** Department of Robotics, Graduate School of Engineering, Tohoku University (01 Aramaki-Aza-Aoba, Aoba-ku, Sendai 980-8579)

\section{1. はじめに}

MEMS (Micro Electro Mechanical Systems) を用いると，セ ンサのようなシステムの鍵を握る部品を, 半導体微細加工

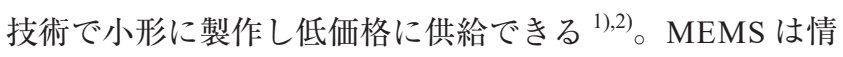
報処理のための LSI と組み合わせて用いられることが多く， このへテロ集積化と呼ばれる技術が盛んに研究されてい る 3),4)。図 1 には MEMS と LSI のへテロ集積化の方法を示 す。(a) は表面マイクロマシニングと呼ばれる方法で, LSI ウェハ上にMEMS を形成するものである。LSI を壊さない ようにMEMSを作る必要があり，温度などで制約される が, MEMS と LSI の結線数を多くできるため, 例えばビデ オプロジェクタ用のミラーアレイなどに用いられている。 (b) はMEMS とLSI を別に作り組み合わせるもので, MEMS 製造時の制約は少ないがワイヤボンディングなどで接続す るため, その結線数などでは制約を受ける。スマートフォ ンのユーザインターフェースに用いる MEMS などに使われ る。(c)のキャリヤウェハに形成した MEMS を LSI ウェハ 上へ転写する方法は，上記のそれぞれの欠点を補うことが できる5)。また (d)のように MEMS ウェハと LSI ウェハを

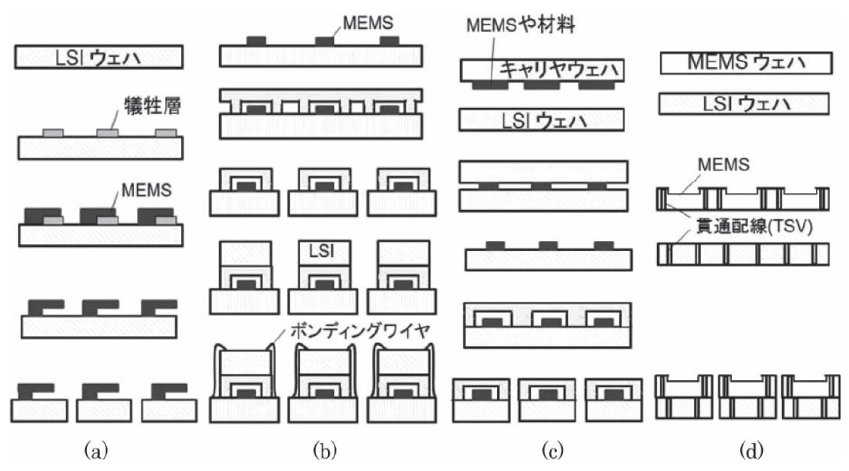

図 1. MEMS と LSIのヘテロ集積化，(a) 表面マイクロマシ ニング, (b) MEMS と LSIの組立, (c) キャリヤウェハ に形成したMEMSのLSIウェハ上への転写, (d) MEMS ウェハと LSI ウェハを重ねて貫通配線 (TSV) 利用
重ね, TSV (Through Si Via) と呼ばれる Si の貫通配線を用 いる方法も，ヘテロ集積化に優れた方法といえる。以下で 述べるように，(c) でLSI ウェハ上に MEMS を転写すると きに, ウェハレベルで一括転写する方法 (2.1), およびキャ リヤウェハからチップレベルで転写する方法 (2.2)がある。 また (d)の TSVも LSI ウェハに形成するもの (3.1), MEMS ウェハに形成するもの (3.2), および両ウェハに形成するも の (3.3) がある。本稿ではこれらを具体例と共に紹介する。

なお MEMS をウェハ工程でパッケージングすることが有 効であるため, このウェハレベルパッケージングを同時に 考えることが重要である ${ }^{6}$ 。

\section{2. キャリヤウェハに形成した MEMS の LSI ウェハ上 への転写}

\section{1 ウェハレベル転写}

図 2 はオペアンプを $20 \times 20$ 配列したLSI 上にボロン添加 ダイヤモンド (BDD) 電極を配列させた, 生体物質検知セン サである ${ }^{7)}$ 。ダイヤモンドは触媒活性を持たないため, 水 を電気分解する電圧が高い。このため生体関連物質などを 電気化学的に酸化・還元する電圧を印加して, これらを検 出するのに適している。ダイヤモンドを堆積するには $800^{\circ} \mathrm{C}$ の温度が必要で, LSI を壊さないようにこれをキャ リヤウェハに形成し LSI に転写している。

図 3 は LSI 上に, 圧電性の $\mathrm{PZT}\left[\mathrm{Pb}(\mathrm{Zr}, \mathrm{Ti}) \mathrm{O}_{3}\right]$ のバイモル フによるスイッチを形成したものである ${ }^{8)}$ 。この PZT はゾ ル・ゲル法で形成してあるが, どの形成方法でも $700^{\circ} \mathrm{C}$ 程 度の高温が必要で, LSI を壊さないようにウェハレベルの 転写で製作した。

\section{2 チップレベル転写}

キャリヤウェハ上の MEMS をLSI チップの一部にだけ転 写し, 残りの MEMS を別の LSI チップに用いることができ る。これには図 4 に示す選択転写技術を使用する ${ }^{9)}$ 。MEMS ウェハをレジストでガラスのキャリヤウェハに張り付けて おき, LSI ウェハ上のバンプに接合した後, ガラス裏面か 


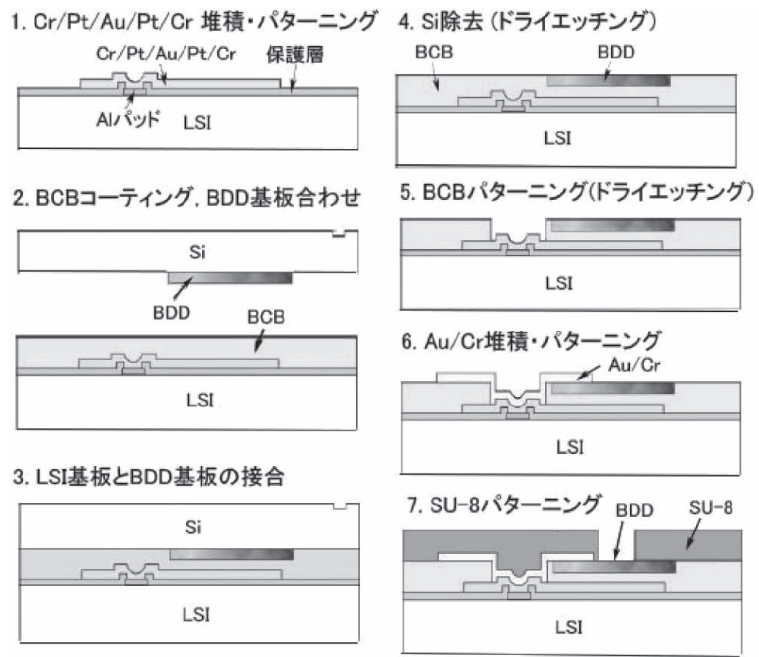

(a)
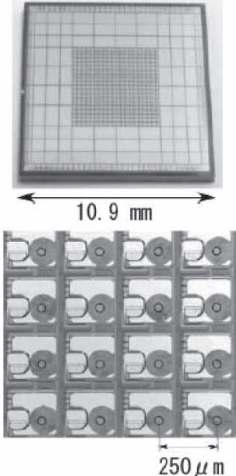

(b)

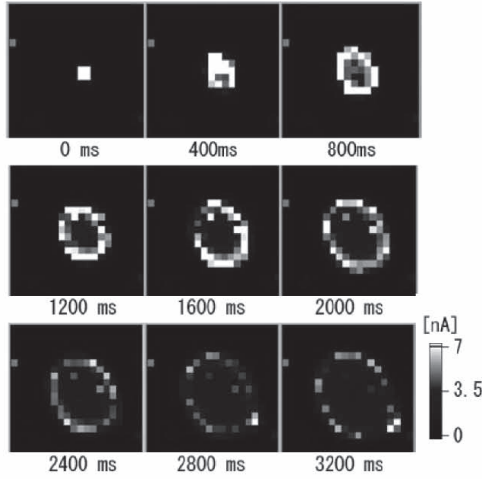

(c)

図 2. LSI 上の $20 \times 20$ ダイヤモンド電極アレイ, (a) 製作 工程, (b) チップ写真とその拡大, (c) ヒスタミンを 中央に滴下したときの広がる様子（利用例）

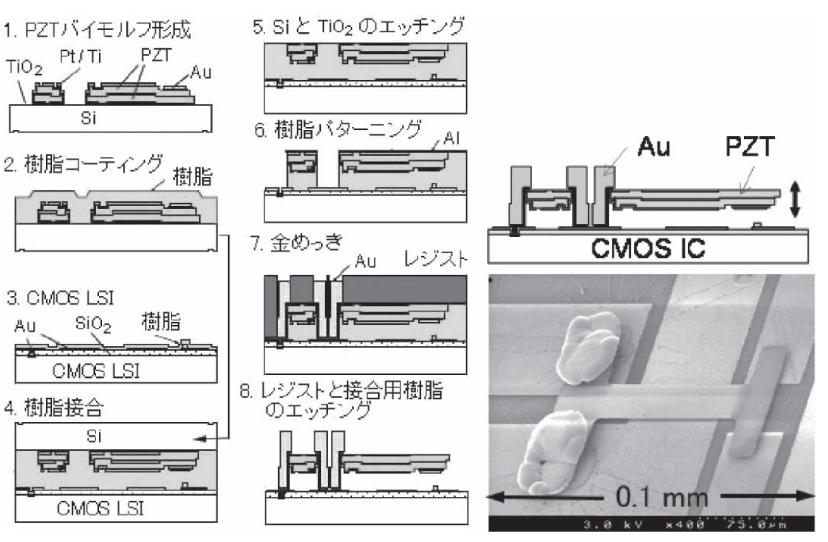

図 3. LSI 上の PZT バイモルフによるスイッチ, 製作工程 と写真

らレーザ光でレジストを炭化し剥離させる（レーザデボン ディング)。

図 5 はこの方法で LSI 上に SAW (Surface Acoustic Wave) フィルタを転写したもので，異なる共振周波数の複数の SAW フィルタをチップ上に形成してある ${ }^{10)}$ 。占有面積が小 さくなるだけでなく, 配線による寄生インダクタンスや寄

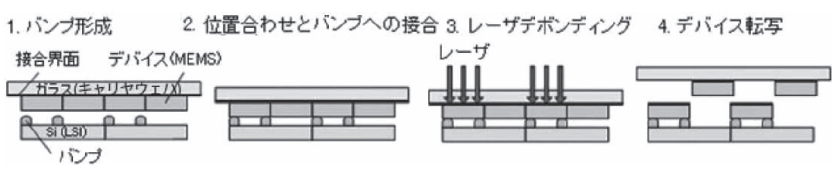

図 4. 選択転写工程
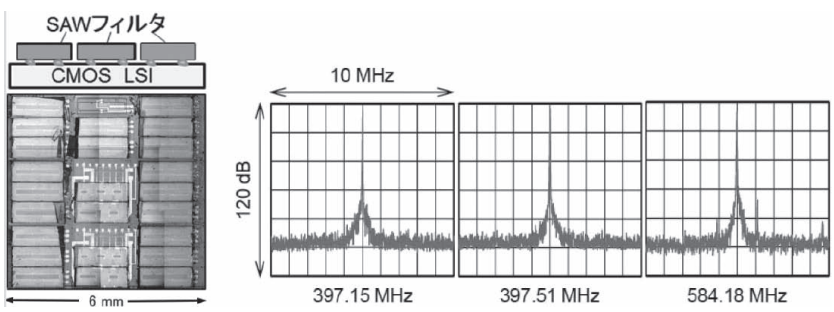

図 5. LSI 上に選択転写した SAW フィルタの写真, 異なる 共振周波数のフィルタ特性
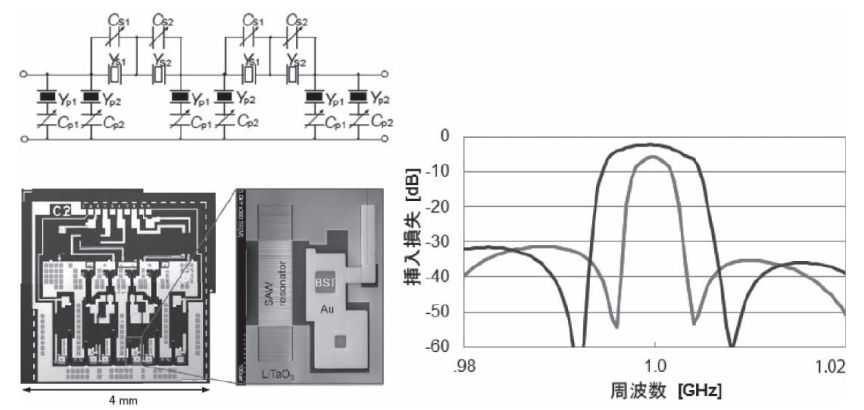

図 6. BST 可変容量を $\mathrm{SAW}$ 用 $\mathrm{LiTaO}_{3}$ 基板上に選択転写し た可変帯域フィルタ（回路，写真，特性）

生容量を減らせる効果がある。

$\mathrm{LiTaO}_{3}$ を用いた $\mathrm{SAW}$ フィルタの基板の上に，強誘電体 の $\mathrm{BST}\left[\mathrm{Ba}(\mathrm{SrTi}) \mathrm{O}_{3}\right]$ を用いた可変容量素子を選択転写して, 可変帯域フィルタを製作した ${ }^{11)}$ 。図 6 にその回路（電圧印 加用抵抗は省略）と写真，および BSTへの電圧を変えたと きの可変帯域特性を示している。

\section{MEMS ウェハとLSI ウェハを重ねて貫通配線 (TSV) 利用}

\subsection{LSI ウェハの貫通配線}

介護ロボットを目的として，人と接触しても安全なよう に体表に形成する触覚センサネットワークを開発してい る。図 7 には, センシングと $45 \mathrm{MHz}$ クロックでのパケッ 卜通信機能を持つ LSI 上に形成した容量型触覚センサの製 作工程，および写真と動作例を示している ${ }^{12)}$ 。LSI に BCB 樹脂 (Benzocyclobutene) で触覚センサ構造を張り付けてお り, LSI ウェハの毫面に TSVで取り出して, フレキシブル の共通配線に接続している。

\subsection{MEMS ウェハの貫通配線}

$100 \times 100$ に配列した電子源としての MEMS ウェハにLSI を貼り合わせた, 超並列電子ビーム描画用アクティブマト リックス電子源を開発している ${ }^{13)}$ 。図 8 には, その製作工 

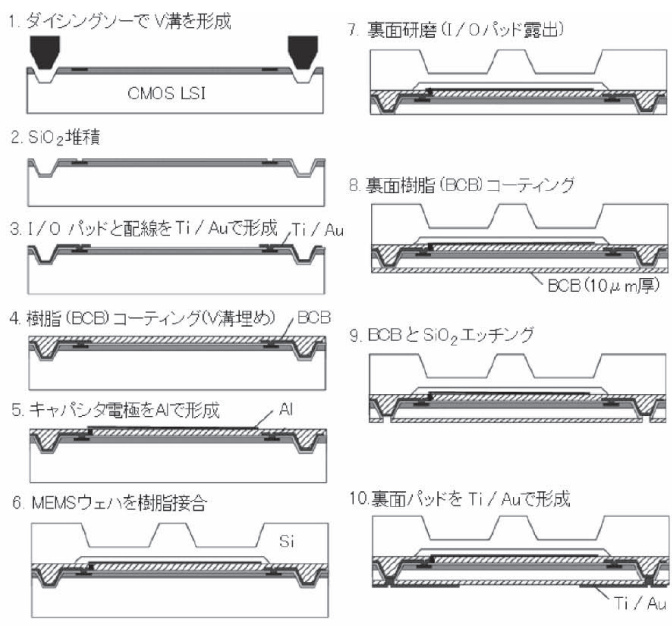

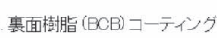
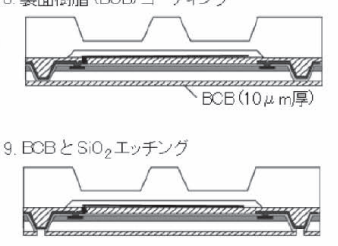

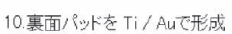

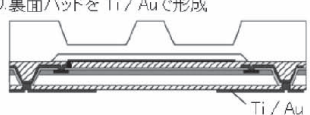

(a)

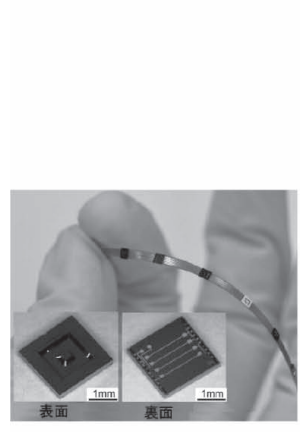

(b)

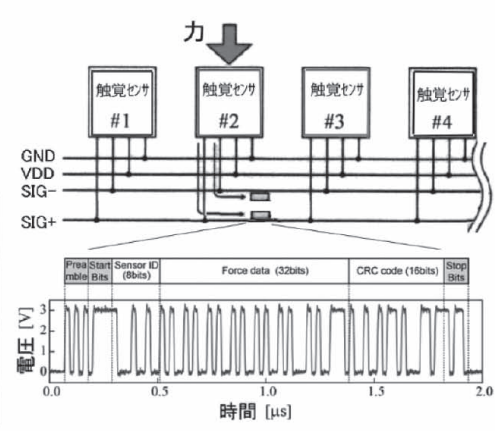

(c)
図 7. LSI に TSV を形成した触覚センサネットワーク，(a) 製作工程, (b) 写真, (c) 動作例
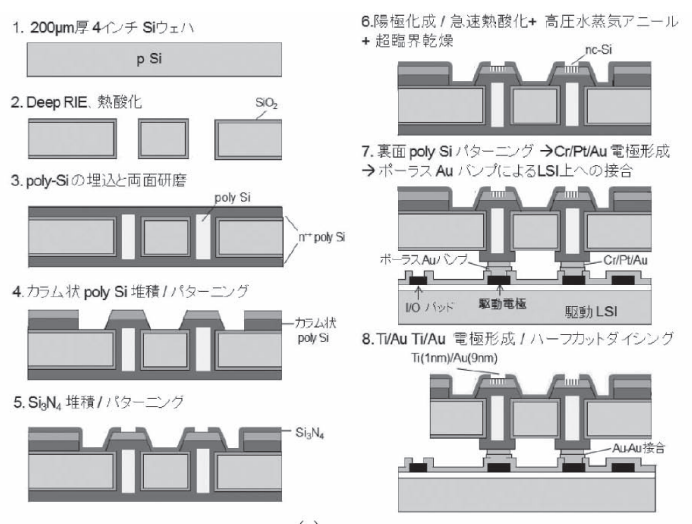

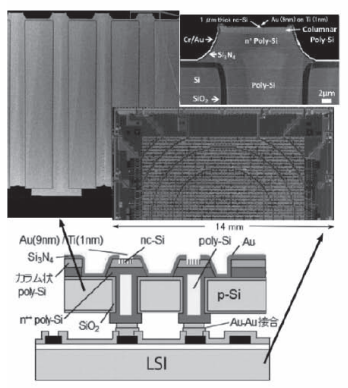

(b)

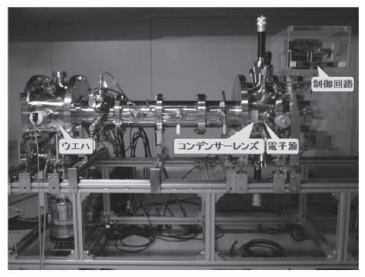

(c)
図 8. 貫通配線付 nc-Si 電子源を用いた $100 \times 100$ アクティ ブマトリックス電子源アレイ, (a) 製作工程, (b) 構 造と写真, (c) $1 / 100$ 縮小型超並列電子ビーム描画実 験装置

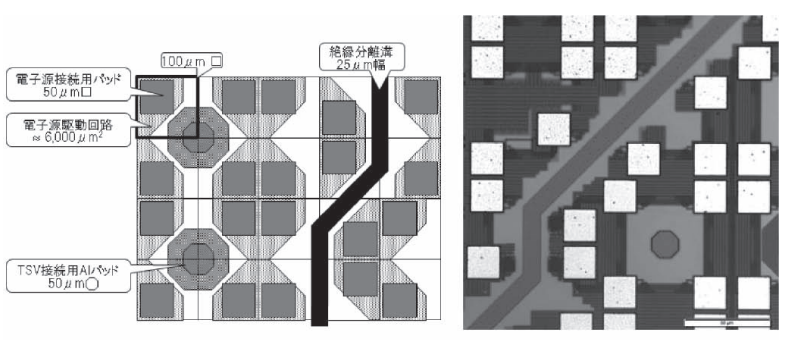

1. 加工前のLSI

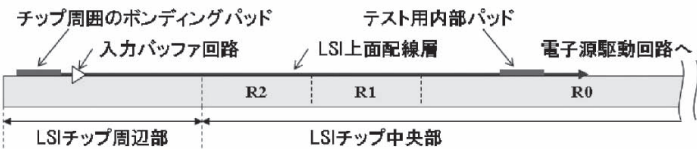

2. 收差補正用の各リングをDeep RIEによるSi貫通满で分離 Deep RIEIこよるSI貫通孔 配線切断

\begin{tabular}{|l|l|l|l|l|l|}
\hline & $\mathrm{R} 2$ & $\mathrm{R} 1$ & $\mathrm{R} 0$ & $\mathrm{R} 0$ \\
\hline
\end{tabular}

3. 貫通满を䋓縁物で埋めて電気的に分離、貫通孔に貫通配線形成

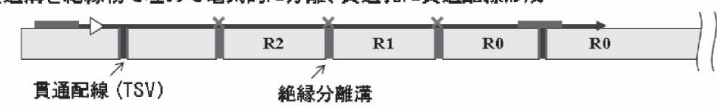

4. 再通配線から各リングに裹面配線

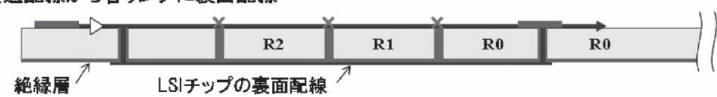

図 9. LSI の絶縁分離と貫通配線（拡大平面構造と製作工 程)

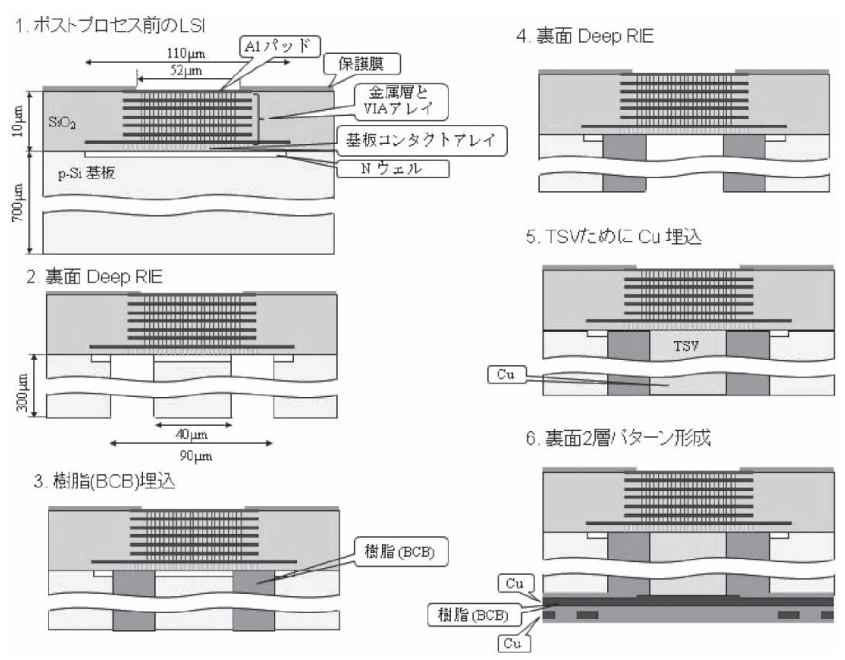

図 10. LSI 貫通配線の製作工程

程，構造と写真，および描画実験装置を示してある。

電子源としては, Si $\mathrm{HF}$ 中で陽極酸化して形成したポー ラス $\mathrm{Si}$ を酸化し，トンネル接合のカスケード構造とした,

ナノクリスタル Si (nc-Si) を用いた。電子が $10 \mathrm{~V}$ 程の電圧 で加速されて放出される。それぞれの電子源から, その MEMS ウェハに形成した poly-Si による TSVで裏面の駆動 用 LSI に接続される。

\subsection{MEMS ウェハと LSI ウェハの貫通配線}

この駆動用 LSI には，図 8(b) のように同心円状のパター ンが見える。これは電圧を印加して電子的な収差補正を行 うものである。このため図 9 のように LSI チップには絶縁 
分離用の溝や, 電気的接続のための TSV を形成した ${ }^{13)}$ 。こ の TSV 付 LSI ウェハを, TSV 付 nc-Si の MEMS ウェハと 重ねて用いる。

LSI に形成するTSV の製作工程を図 10（前ページ掲載） に示す。LSI 表面の金属配線層に裏面から $\mathrm{Cu}$ の TSV がつ ながるようになっている。

\section{4. おわりに}

キャリヤウェハに形成した MEMS の LSI ウェハ上への転 写, およびMEMS ウェハと LSI ウェハを重ねて TSVによ り接続したり配線を取り出したりする方法について, 具体 例を示した。多様な目的に応え, 高性能化をもたらすへテ 口集積化技術として有用である。

(2017.6.17- 受理)

\section{文献}

1) 江刺正喜 : “はじめての MEMS,” 森北出版, 2011

2) 江刺正喜, 小野崇人：“これからのMEMS－LSI との融 合一, ”森北出版, 2016

3) M. Esashi and S. Tanaka: "Heterogeneous Integration by Adhesive Bonding," Micro and Nano Systems Letters, Vol. 1, No. 3, 2013

4) A. C. Fischer, F. Forsberg, M. Lapisa, S. J. Bleiker, G. Stemme, N. Roxhed, and F. Niklaus: "Integrating MEMS and ICs," Microsystems \& Nanoengineering, Vol. 1, p. 15005, 2015

5) M. Esashi and S. Tanaka: "Stacked Integration of MEMS on LSI," Micromachines, Vol. 7, No. 8, p. 137, 2016

6) M. Esashi: "Wafer Level Packaging of MEMS," J. of Micromechanics and Microengineering, Vol. 18, No. 7, p. 073001, 2008

7) K. Y. Inoue, M. Matsudaira, M. Nakano, K. Ino, C. Sakamoto, Y. Kanno, R. Kubo, R. Kunikata, A. Kira, A. Suda, R. Tsurumi, T. Shioya, S. Yoshida, M. Muroyama, T. Ishikawa, H. Shiku, S. Satoh, M. Esashi, and T. Matsue: “Advanced LSI-based Amperometric Sensor Array with Light-shielding Structure for Effective Removal of Photocurrent and Mode Selectable Function for Individual Operation of 400 Electrodes," Lab on a chip, Vol. 15, pp. $848-856,2015$

8) K. Matsuo, M. Moriyama, M. Esashi, and S. Tanaka: “Low-voltage PZT-actuated MEMS Switch Monolithically Integrated with CMOS Circuit," Technical Digest IEEE MEMS 2012, pp. $1153-$ 1156, 2012

9) T. Samoto, H. Hirano, T. Somekawa, K. Hikichi, M. Fujita, M.
Esashi, and S. Tanaka: "Wafer-to-wafer Transfer Process of Barium Strontium Titanate Metal-insulator-metal Structures by Laser Preirradiation and Gold-gold Bonding for Frequency Tuning Applications," Transducers2013 \& Eurosensors XXVII, pp. $171-174,2013$

10) S. Tanaka, M. Yoshida, H. Hirano, and M. Esashi: "Lithium Niobate SAW Device Hetero-transferred onto Silicon Integrated Circuit Using Elastic and Sticky Bumps," 2012 IEEE International Ultrasonics Symposium, pp. 1047-1050, 2012

11) H. Hirano, T. Kimura, I. P. Koutsaroff, M. Kadota, K. Hashimoto, M. Esashi, and S. Tanaka: "Integration of BST Varactors with Surface Acoustic Wave Device by Film Transfer Technology for Tunable RF Filters," J. of Micromechanics and Microengineering, Vol. 23, No. 2, p. 025005, 2013

12) M. Makihata, S. Tanaka, M. Muroyama, S. Matsuzaki, H. Yamada, T. Nakayama, U. Yamaguchi, K. Mima, Y. Nonomura, M. Fujiyoshi, and M. Esashi: "Integration and Packaging Technology of MEMS-on-CMOS Capacitive Tactile Sensor for Robot Application Using Thick BCB Isolation Layer and Backsidegrooved Electrical Connection," Sensors and Actuators A, No. 188, pp. $103-110,2012$

13) M. Esashi, A. Kojima, N. Ikegami, H. Miyaguchi, and N. Koshida: "Development of Massively Parallel Electron Beam Direct Write Lithography Using Active-matrix Nanocrystalline-silicon Electron Emitter Arrays," Microsystems \& Nanoengineering, Vol. 1, p. 15029,2015

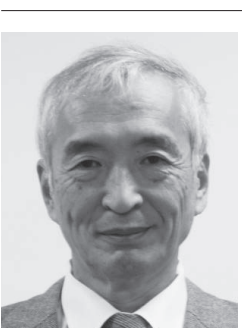

江刺正喜（えさし まさよし）

著者紹介

昭和 46 年東北大学工学部電子工学科卒。 51 年 同大学院博士課程修了。同年より東北大学工学部 助手， 56 年助教授，平成 2 年より教授となり現在 (マイクロシステム融合研究開発センター), (兼) 革新的イノベーション研究機構 (COI)（リサーチ フェロー）に至る。半導体センサ，マイクロシス テム, MEMS の研究に従事。

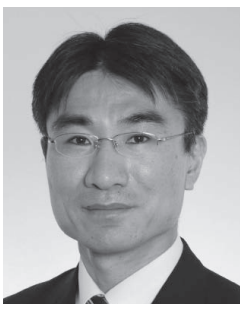

田中秀治（たなかしゅうじ）

平成 11 年東京大学大学院工学研究科産業機械工 学専攻 博士課程修了。同年より東北大学大学院工 学研究科助手, 13 年講師, 15 年助教授, 25 年教 授となり現在（大学院工学研究科ロボティクス専 攻）に至る。産業に関連する MEMS 技術，特に集 積化技術，MEMS パッケージング技術，弾性波デ バイス, 圧電デバイス・材料などの研究に従事。 